\title{
Health authority commissioning for quality in contraception services
}

\author{
Mark Newman, Martin Bardsley, David Morgan, Bobbie Jacobson
}

\begin{abstract}
Objective-To compare the commissioning of contraception services by London health authorities with accepted models of good practice.

Design-Combined interview and postal surveys of all health authorities and National Health Service (NHS) trusts responsible for running family planning clinics in the Greater London area.

Main outcome measures-Health authority commissioning was assessed on the presence of four key elements of good practice-strategies, coordination, service specifications, and quality standards in contracts-by monitoring activity and quality.

Results-Less than half the health authorities surveyed had written strategies or service specifications for contraception services. Arrangements for coordination of services were limited and monitoring was underdeveloped.

Conclusion-The process of commissioning services for contraception seems to be relatively underdeveloped despite the importance of health problems associated with unplanned pregnancy in London. These findings raise questions about the capacity of health authorities to improve the quality of these services through the commissioning process.

(Quality in Health Care 1998;7:142-148)
\end{abstract}

School of Health,

Biological, and

Environmental

Sciences, Middlesex

University, 10 Highgate

Hill, London, UK

Mark Newman, senior

lecturer, Health of

Londoners Project

Martin Bardsley, project

manager, Health of

Londoners Project

David Morgan, health analyst

Bobbie Jacobson, director of public health, East of

London and City Health

Authority

Correspondence to:

Dr Mark Newman, School of

Health, Biological, and

Environmental Sciences,

Middlesex University, 10

Highgate Hill, London N19

5ND, UK. Telephone 0044

181362 6627; fax 0044181

3626299 .

Accepted for publication

2 July 1998
Keywords: commissioning for quality; contraception

\section{Introduction}

The provision of contraception is an important part of local health services. In London the National Health Service (NHS) spends about $£ 21$ million a year on contraception and has a network of over 300 family planning clinics and 1800 general practitioner (GP) partnerships delivering services to a population of 1.8 million women between the ages of 15 and 55 (box 1). Yet of the 400 female residents of London who conceive every day, up to $50 \%$ will not have intended to do so. Every day about 330 female residents of London obtain emergency contraception and about 170 will have an abortion. ${ }^{1}$

Socioeconomic and cultural factors are likely to be more influential than the provision of services for contraception in determining conception rates $^{3}$ but the rationale for the public provision of contraception services is well recognised, ${ }^{4}$ and there seems to be good evidence of the cost effectiveness of the public provision of contraception. ${ }^{5-7}$ Implicit in public
In 1991 the structure and operation of the United Kingdom health service was reorganised to separate the functions of service provision from the purchasing or commissioning of services. Health authorities were no longer responsible for the actual provision of services but had to ensure that quality services were provided to meet locally assessed need. With the exception of services provided through general practice, the actual provision of NHS services became the responsibility of newly constituted semi-independent NHS trusts.

The NHS trusts can be broadly divided into two types. Acute trusts are largely based on hospital sites and provide mainly in patient emergency health care and follow up. Community trusts usually provide little inpatient care and are not generally concerned with emergency health care. In the case of contraception services surgical methods are usually provided by acute trusts whereas family planning clinics are provided by community trusts.

In 1974 contraception became freely available on the NHS and in 1975 GPs became part of the NHS family planning service. The GPs provide contraception services as part of the general healthcare services available to their practice population. The GPs may also provide contraception services to people not registered with their practice. Family planning clinics provide contraception services as part of a range of sexual health services and may be used by anyone regardless of their area of residence. London Brook Advisory Centres are a non-statutory organisation which provide contraception services specifically for young people. Brook has its own centres but also provides sessions at local family planning clinics.

In England and Wales it is estimated that $70 \%$ of medical non-surgical contraception services are provided by GPs, $25 \%$ from family planning clinics and $3 \%$ from hospitals. $^{2}$

Box 1 Provision of contraception in England since 1991.

policy is the aim that each pregnancy should be wanted, ${ }^{8}$ and government policy since 1974 has emphasised the need for choice of agency and comprehensiveness of provision. ${ }^{9-14}$ The Health of the Nation established HIV/AIDS and sexual health as one of the key areas of United Kingdom health policy (box 2). ${ }^{15}$

After the 1991 NHS reforms, district health authorities acquired major new responsibilities 
Since 1991 the framework for the promotion of health in England has been provided by The Health of the Nation strategy. The strategy identified five key priority areas, one of which was HIV/AIDs and sexual health. In each key area targets were identified and potential strategies outlined. The targets relevant to provision of contraception were reducing the rate of conceptions among the under $16 \mathrm{~s}$, reducing the rate of unwanted pregnancies, and ensuring the provision of effective contraception services for those people who want them. The framework emphasises the potential role of contraception services in promoting sexual health. ${ }^{16}$ However, there has been no detailed specification of the level or range of contraception services that health authorities should ensure is provided.

The Labour Government elected in 1997 has launched a consultation document on a new framework for the promotion of health. New priority areas have been identified which do not (at present) include sexual health. ${ }^{17}$ However, the government has set up four national task groups to tackle the problem of unwanted pregnancy.

Box 2 Government health policy on contraception in England.

for the commissioning of services on the basis of need ${ }^{18}$ The distinction introduced between purchaser and provider should have enabled health authorities as commissioning agencies to develop systems for assessing and defining more clearly the volume and quality of services in a way that is consistent with a strategy for improving health within their own area (box 3). Health authorities thus have a clear remit to improve the quality of services through commissioning. It is therefore important to assess the ways in which health authorities are undertaking this task. ${ }^{19}$ Furthermore, as an editorial in this journal argued, assessing and improving the quality of contraception services is an urgent priority, ${ }^{20}$ particularly given England's (and especially London's) continuing record of comparatively poor health outcomes in the field of sexual health. ${ }^{121}$

This paper reports the results of linked surveys of health authority and NHS trust commissioning and provision of contraception services. This was carried out as part of a wider study of the need for and provision of contraception and abortion services in the Greater London area. ${ }^{1}$ This paper reports on the findings of the study relative to one of the objectives which was to compare the commissioning of contraception services by London health authorities to accepted models of good practice.

Part of the wider study was concerned with assessing the need for services and therefore the part of the study reported here concentrated on four common elements that are accepted as good practice in commissioning services of any type (box 3):
Provision of contraception by GPs is funded from a health authority's non-cash limited general medical services budget. Contraception through family planning clinics is funded from a health authority's cash limited hospital and community health services allocation. There are different models of how commissioning should be undertaken but all follow a similar pattern ${ }^{22}$ :

- Assess the level of local need for a particular service

- With adequate account of cost effectiveness, views of other commissioning agencies-for example GPs, providers, and service users-decide how the service should be provided (often expressed in the form of a strategy)

- Purchase the required volume of services at a specified quality (made explicit in a service specification which is part of the service contract)

- Monitor the delivery of services against the specification in the contract.

Health authorities may use different types of contracts with trusts or independent providers-such as London Brook. The most common form of contract used for contraception services was a block contract. These can operate in several ways but usually mean when the health authority buys a service for a fixed amount each year without specifying in detail either the cost of each individual item or the volume of work to be carried out. Unlike provision through trusts, a health authority's responsibility for the quality of general practice services is not carried out through a contract mechanism. Instead health authorities have to rely on their influence through policy and practice on training, recruitment, the work of health promotion departments, their pharmaceutical advisors, and the Medical Audit Advisory Group, for example. New commissioning arrangements will be introduced in 1999. Many of the health authorities' commissioning responsibilities are to be transferred to newly created Primary Care Groups $^{23}$. However, the principle of the division between commissioning and provision will remain and thus the new bodies will still need to follow a variation of this process.

Box 3 Commissioning services.

\section{STRATEGY}

The Health of the Nation key area handbook for sexual health emphasises the importance of developing an overall local strategy. ${ }^{16}$ The term strategy can refer to several different levels or types of strategic planning, and the elements of a local strategy will vary according to local circumstances. The strategy stipulates the way in which services will be provided and coordinated, contains aims and objectives, may set process or outcome indicators, state monitoring arrangements, and set priorities for future years. $^{24}$ 
COORDINATION

Contraception services are provided through general practice and community and acute trusts and encompasses aspects of health promotion and work in non-NHS sectors. Coordination of service provision is therefore of added importance. This can be facilitated by the presence of a single coordinator within the commissioning agency and the formation of a local joint planning group. ${ }^{16}$

\section{SERVICE SPECIFICATIONS AND STANDARDS IN} CONTRACTS

A basic indicator of quality in the contracting process is whether or not there is a specification for a particular service. Other basic quality indicators are the presence of standards for service provision for young people and minority ethnic groups as highlighted in the Health of the Nation Key Area Handbook. ${ }^{16}$ An additional quality standard is the extent to which a specification promotes access to a wide range of appropriate contraceptive methods. Health authorities were asked about commissioning of methods which, although of proved effectiveness, anecdotal evidence suggested were difficult to access in certain parts of London-that is, hormonal implants, ${ }^{25}$ hormonal intrauterine contraceptive devices (IUCD) (Mirena), ${ }^{26}$ emergency or postcoital contraception, and male and female surgical sterilisation. ${ }^{27}$ Our study of NHS provision of these services through trusts and general practice confirmed widespread variation in use and availability. ${ }^{1}$

Health authorities have a responsibility for ensuring the quality of contraceptive services provided through general practice. Indicators of quality here are that health authorities know the availability of GPs and practice nurses trained in family planning, fund the provision of condoms and pregnancy testing in general practices, and coordinate general practice provision with other sources of provision.

\section{MONITORING}

The reporting of activity and quality information against the contract specification is an essential part of the commissioning process. A quality indicator in this area is that health authorities and trusts can report on all the activity and quality data relevant to the provision of contraception services.

\section{Methods}

SAMPLE

The sample for this part of the study was the 16 health authorities in the greater London area and the 27 community trusts which provide contraception through family planning clinics. Questionnaires were sent to the directors of public health in each health authority and to the director of womens' services or service manager of the family planning clinic in each trust.

DATA COLLECTION

Data were collected with a semistructured questionnaire designed for this study with items drawn from the model for provision of contraception service developed by the Family
- Strategy

- Local planning

- Young people

- Minority ethnic or cultural groups

- Activity data

- Staffing resources (trust only)

- Staff training (trust only)

- Profile of sites (trust only)

- Sterilisation (health authority only)

- Emergency contraception (health authority only)

- GP services (health authority only).

\section{Box 4 Questionnaire modules.}

Planning Association. ${ }^{28}$ The model is recommended in the Health of the Nation key area handbook for HIV/AIDS as one which commissioners can use as a guide for writing the level, range, and quality of services into the contract. ${ }^{16}$ The items in the district model were used as standards which formed the basis of the questionnaire. Items were grouped into modules under the headings already mentioned plus additional modules related to specific categories of provision or commissioning of services (box 4). Additional semistructured questions were included to allow respondents to raise other issues of importance relative to commissioning or provision of services.

Data collection took place during the period July 1996 to March 1997. Data from the trusts were collected by postal survey only and from the health authorities by postal survey and face to face interview. The questionnaire was sent to the directors of public health several weeks before carrying out a prearranged interview. Semistructured interviews were carried out by a field worker employed by MORI (a commercial research and management company) and were used to ensure that the questionnaire was completed. In some cases other members of the health authority staff were present at the interview. Invariably not all of the information requested was provided at the interview and the questionnaire was left with the interviewee for them to obtain the outstanding information. Members of the research team followed up the individual health authorities and trusts to obtain missing data.

\section{DATA ANALYSIS}

Data were analysed with Excel. Simple descriptive and comparative data analysis was carried out. The primary aim of the analysis was to provide a description of commissioning and provision of services and to identify where standards were not met. The data provided by both the health authorities and the trusts were used to compile profiles for each health authority area. The profiles contained demographic data about the health authority, information about local sexual health indicators - for example, fertility rates - details of health authority commissioning arrangements, and details of local service provision, including information about local GP prescribing. ${ }^{29}$

The research team went to considerable lengths to verify the accuracy of the data 
Table 1 Health authority strategies for contraception services

\begin{tabular}{lcc}
\hline Question & Yes & No \\
\hline Does the health authority have a strategy for contraception services? & 5 \\
Does the health authority have a strategy for contraception services for young people? & 11 \\
Does the health authority have a strategy for contraception services for minority ethnic or cultural groups? & 11 & 11 \\
\hline
\end{tabular}

reported and their interpretation of it. The profiles developed with the reported data were returned to the health authorities (to the director of public health or another person nominated by them) and to the individual trusts (to the senior medical officer responsible for the family planning service, or the service manager) for verification. This produced a high level of response and appropriate corrections to the data were made. Asking the health authorities and trusts the same questions allowed for further checks on the reliability of reporting.

\section{Results}

A $100 \%$ response rate was achieved from both the 16 health authorities and the 27 trusts. Where health authority and trust could be matched - that is, the local trust provided contraception services under contract for only one health authority-their answers were compared.

\section{STRATEGY}

The survey asked the 16 health authorities whether they had a written strategy for contraception services generally, for the provision of contraception services for young people and minority ethnic groups specifically, and for abortion. Table 1 shows the main results in this area. Six health authorities had no strategy at all for the provision of contraception services and five had them for young people only. Five health authorities had neither a family planning strategy or service specification. Another way of interpreting this is to say that about 2.5 million London residents live in health authorities where there is no strategic framework for contraception provision.

COORDINATION

None of the health authorities had a single lead person coordinating all aspects of contraception commissioning. The background of the identified lead person or contacts in each health authority varied. In some health authorities it was a person in the Department of Public Health, in others a commissioning manager, and in others a primary care manager. None of the identified contacts were able to supply all of the information requested and only five were able to easily access basic activity and data about waiting times for all provision of contraception. There seemed to be little coordination of provision of contraception services in general practice with any other form of service provision.

Eleven health authorities reported that there were forums operating in their area where the provision of contraception was discussed. Providers of male or female sterilisation services were rarely included in the membership of such groups. When the responses from the health authorities were compared with those of their local contraception service providers, there were some differences of opinion about the extent of local joint planning. In those health authorities where a purchaser could be directly matched to a particular provider trust $(n=13)$, only in seven did both the purchaser and the provider state that there was a joint planning forum.

SERVICE SPECIFICATIONS AND STANDARDS IN CONTRACTS

Health authorities used several different types of contract. Non-surgical methods of contraception were usually purchased as part of a block contract with a local community trust and in some cases directly with London Brook. Sterilisation was usually subsidiary within a block surgical, gynaecological, or urological contract with the local acute trust (see box 3 for further explanation of the different types of contract).

Eight health authorities had specifications for contraception services. Six health authorities had some strategic elements relating to young people. In two of these contraception was placed within a broader young peoples' health strategy. Five had service specifications for young people. Specifications were most developed where they concerned contracts with specialist providers for young people - for example, with London Brook.

As the results in table 2 indicate, when specifications for services for minority ethnic groups were reported it was not clear whether these specifications were for all services or specifically for contraception. In three health authorities there were no service specifications for provision of contraception service for minority ethnic groups at all. The standards most often included were for female doctors and interpreting services to be available. Very few health authorities specified that bilingual advocacy or written information in mother tongue languages should be available.

None of the health authorities had a formal strategy or specification for the provision of emergency contraception, although in six it was clear that some action had been taken to improve its accessibility. With the exception of one health authority, which had introduced criteria for the provision of Mirena, none had strategies or specifications that promoted or restricted access to any particular methods of contraception. None of the health authorities had specific quality criteria for the provision of sterilisations and only five were able to say how many they had purchased in the past year or to provide information about waiting times.

Health authorities' claims about the standards included in their service specifications were compared with the reports from the trusts in their area that were subject to these specifications. The results of the comparison suggest 
Table 2 Service standards for minority ethnic or cultural groups

\begin{tabular}{lcc}
\hline Which of the following are included? & Yes & No or no answer \\
\hline Ethnic monitoring & 7 & 6 \\
Availability of female doctors & 10 & 3 \\
Interpreting services & 10 & 3 \\
Bilingual health advocacy services & 3 & 6 \\
Audiovisual materials in mother tongue languages & 7 & 12 \\
Written materials in mother tongue languages & 1 &
\end{tabular}

Table 3 Health authority mechanisms for monitoring contraception services

\begin{tabular}{lrl}
$\begin{array}{l}\text { What are the mechanisms for monitoring or auditing } \\
\text { contraception services purchased? }\end{array}$ & Yes & No or no answer \\
\hline Activity data & 13 & 3 \\
Clinical audit programme & 9 & 7 \\
Contract review meetings & 11 & 5 \\
Quality review meetings & 7 & 9
\end{tabular}

that even where a standard is specified it does not always lead to provision. It should also be noted that in several areas, although the health authority may not have specified a particular feature of the contraception service, the local trust was nevertheless offering them.

Information supplied by health authorities about the number of general practices without female doctors or the availability of staff trained in family planning was patchy. Five health authorities were able to say whether or not there were practices in their area with only male GPs and no nurses qualified in family planning. Nine health authorities stated that in all or some of the practices in their area there was access to free condoms. Five health authorities funded practice based pregnancy testing schemes. Six health authorities had a contraception training and education plan for staff working in general practice.

\section{MONITORING}

Health authorities were asked which mechanisms were used to monitor the provision of contraception and abortion services. Monitoring may be more limited than the results in table 3 suggest. Most health authorities could not supply activity data on these services on request. In only three out of 11 health authorities where contract review meetings were reported by the health authority, did the trusts in that area report the same mechanism. In only one out of the seven health authorities who reported having quality review meetings did the trusts report the same mechanism.

\section{Discussion}

At the time of this study most London health authorities had not developed a strategic approach to the commissioning of contraception services. Service specifications for contraception, where they existed, were underdeveloped and monitoring of the quality of services haphazard. Service specifications did not seek to promote effective methods of contraception, but with one exception, neither did health authorities report directly seeking to restrict access to any particular method of contraception. Health authorities did not seem to be playing an active part in the promotion or monitoring of provision of contraception through general practice and coordination of the different services providing contraception seemed haphazard.

To our knowledge the study on which this paper is based represents one of the most comprehensive attempts to assess the quality of commissioning and provision of contraception services. The absence of any reference to the role of health promotion and education in the study should not be interpreted as a lack of recognition of the key part that these interventions play in the prevention of unwanted pregnancy. ${ }^{30}$ Similarly the importance of the part played by contraception services provided by general practice is not adequately reflected in this study. The research team are about to embark on a more in depth study of contraceptive services provided by general practice. Similarly, questions about the effectiveness of different patterns of provision of services were not considered. The type of study carried out does not allow a rigorous or unambiguous analysis of which patterns of provision are most effective.

Studies based on self reported data are inevitably reliant on the quality of responses and on the availability of information. The inability of many respondents to supply the data and the conflicting reports received from health authorities and trusts mean that the results must be interpreted cautiously. All of the results presented here were returned to the health authorities and trusts for validation. However, the study does not contain information which corroborates the perspectives of health authorities and trusts on their performance with service users' experience.

The limited comparisons with previous studies that are possible suggest that in some parts of London there have been dramatic changes in the provision of family planning clinic services since $1989^{31}$ and to a lesser extent since $1992 . .^{32-34}$ These changes have occurred across London in inner city, urban, and suburban areas. Allthough marked variation in patterns of service provision were found, the apparent deficits in commissioning arrangements followed no discernable pattern.

At a local level the pace of organisational change makes it difficult to tease out the contribution of commissioning itself to any changes in the volume, comprehensiveness, and quality of service provision. ${ }^{35}$ Although there are some health authorities that are supporting innovative work in a particular area, it seems clear that most health authorities in London have not made adequate investment in the process of commissioning contraception services. The results of this and other studies of the commissioning process ${ }^{36-38}$ suggest that it is doubtful that any changes that have occurred in arrangements for provision of services are the results of any deliberate strategic action to improve quality through the commissioning process.

The design of this study did not allow the identification of reasons why commissioning in this area seemed to be underdeveloped. Gill ${ }^{135}$ has suggested that there are several reasons to be sceptical about the ability of commissioners to improve the quality of service provision. 
(a) Have the contraception needs of the local population been assessed?

(b) Does coverage from local providers match the needs of the local population?

(c) How well developed is purchasing of contraception services with regard to:

- A lead person coordinating

- Service specifications

- An agreed interagency strategy promoting effective methods of contraception

(d) Do services meet the needs of special groups, particularly:

- Young people

- Minority ethnic groups and those whose first language is not the majority language

- Men

(e) Are comprehensive activity data available from all relevant sources including:

- Providers of surgical methods of contraception

- All providers of prescription only methods of contraception

- All providers of postcoital or emergency contraception.

Box 5 Considerations for commissioners of contraception services.

Firstly, because financial pressures cause commissioners to focus on volume and price. This is particularly the case in the field of provision of contraception where there are numerous, largely uncoordinated, providers of open access services, on which a comparatively small part of an individual health authority's budget is spent. Secondly, Gill argues that there are deficiencies in the quality and flow of information which is confirmed in our findings. Thirdly, because of a lack of progress in generating indicators of appropriateness - that is, how does a health authority decide what constitutes quality provision of service-a particular problem in the field of contraception. To these we would add a fourth, a lack of resources, skills, and knowledge within commissioning organisations themselves. As well as pressures to contain or reduce expenditure on services health authorities were also under pressure to reduce their own costs.

Although the underdevelopment of commissioning for these services may come as no surprise, the question remains as to whether it is possible for commissioning authorities to do anything much about the quality of provision of local services. Muir Gray suggested that purchasers have some evidence based tasks due to their control over resource allocation. ${ }^{39}$ The results of this study suggest that resource allocation in the absence of detailed service specification and monitoring of service quality will not necessarily lead to cost effective appropriate patterns of service provision.

The changes being introduced as a result of the 1997 white paper ${ }^{23}$ may provide a welcome space for commissioning organisations to place more focus on quality issues. The renewed emphasis on cooperation between health, local authority, and voluntary sectors should create further opportunities to improve the coordination of services. However, the dominant theme of United Kingdom health policy remains one of cost reduction in general, and a reduction of so called management costs in particular. This suggests that the newly constituted primary care groups will continue to struggle to devote the necessary time, energy, and resources to the commissioning of services-such as contraception - which consume a comparatively small amount of the healthcare budget.

Policy makers need to ensure that standardised methods for the collection of information on the quality of provision of contraception are developed and made available to commissioners and purchasers. Also, the importance of a strategic approach to planning for quality provision of services should be emphasised to commissioning groups. As a first step towards improving the quality of local contraception services commissioning agencies should consider the questions outlined in box 5, and where deficiencies are identified develop a strategic collaborative approach to remedy the situation.

1 Newman M, Bardsley M, Morgan D, et al. Contraception and abortion services in London: are we meeting the need? London. Health of Londoners Project, 1997.

2 Office of Population Censuses and Surveys. General Household Survey 1993. London: HMSO, 1995.

3 Jones EF, Forest JD Goldman N. Teenage pregnancy in industrialised countries: determinants and policy implications. Fam Plann Perspect 1985;17:53-63.

4 Health Education Authority. Health update 4: sexual health, 2nd edition. London: HEA, 1997

5 Hughes D, McGuire A. The cost effectiveness of family Hughes D, McGuire A. The cost effectiveness of family
planning provision. F Public Health Med 1996;18:189-96.

planning provision. F Public Health Med 1996;18:189-96.
Lee PR, Stewart FH. Failing to prevent unwanted pregnanLee PR, Stewart FH. Failing to prevent unwanted
cies is costly. Am $\mathcal{F}$ Public Health 1994:84:479-80.

7 Trussell J, Leveque JA, Koenig JD, et al. The economic value Trussell J, Leveque JA, Koenig JD, et al. The economic value
of contraception: a comparison of 15 methods. Am f Public Health 1995;85:494-503.

8 Ashton JR, Marchbank A, Mawle P, et al. Family planning, abortion and fertility services. Healthcare needs assessment. London. Department of Health. 1992:21

9 Department of Health. Family Planning Service: memorandum of guidance. London. Department of Health, 1974. (Health Service Circular (1S) 32.)

10 Department of Health. Health services development. London: Department of Health, 1988. (Health Circular (88)43.)

11 Department of Health. Executive Letter (90) MB/24 and Family Planning Circular 18/90. London: Department of Health, 1990.

12 Department of Health. Executive Letter (90)MB/115. London: Department of Health, 1990.

13 Department of Health. Executive Letter (91)63. London: Department of Health, 1991

14 Department of Health.Guidelines for reviewing family planning services. London: Department of Health, 1992 (Health Service Guidelines (92)6.)

15 Department of Health. The Health of the Nation: a strategy for health in England. London: HMSO, 1992.

16 Department of Health. The Health of the Nation key area handbook: HIVIAIDS and sexual health. London: HMSO, 1993.

17 Department of Health. Our healthier nation: a contract for health - a consultation paper. London: The Stationary Office, 1998. (Cmd 3852.)

18 Audit Commission. Their health, your business: the new role of the district health authority. London: HMSO, 1993.

19 De Wildte G, Bhopal R, Lavender M. Research into purchasing health care: time to face the challenge. $\mathcal{F}$ Epidemiol Community Health 1996;50:611-2.

20 Smith C. Measuring quality in contraceptive services. Quality in Health Care 1997:6:59.

21 Adler MW. Sexual health-a Health of the Nation failure. BMF 1997;314:1743-7.

22 CASPE. Literature review in the area of quantitative variables to support effective purchasing. London: North Thames NHSE, Organisation and Management Research and Development Programme, 1997.

23 Department of Health. The new NHS, modern, dependable. London: HMSO, 1997.

24 Ovretveit J. Purchasing for health. Buckingham: Open University Press, 1995.

25 Sivin I. International experience with Norplant and Norplant II contraceptives. Stud Fam Plann 1996;19:8194. 
26 Chi I. The Tcu 380A (Ag), MLCU 375 and Nova T IUDs and the IUD daily releasing $20 \mathrm{mg}$ levonororgestrel-four pillars of IUD contraception for the nineties an Contraception 1993;47:325-47.

27 Loudon N, Glasier A, Gebbie A, eds. Handbook of family planning and reproductive health care, 3rd edition. Edinburgh Churchill Livingstone, 1995.

28 Family Planning Association. Family planning services: a model for district health authorities. London: Family Planning Association, 1990.

29 Newman M, Bardsley M, Morgan D, et al. Contraception and abortion services in London. Vol 2. Health Authority profiles. London: Health of Londoners Project, 1997.

30 Centre for Reviews and Dissemination (CRD). Preventing and reducing the adverse effects of unintended teenage pregnancies. Effective Health Care 1997;3.

31 Kenmir B. Family planning clinic cuts. London: Family Planning Association, 1990.

32 Bhatti N. A review of family planning services in City and Hackney. London: City and Hackney District Health Hackney. London:
33 Newham District Health Authority. Newham family planning review 1992. London: NHDA, 1992.

34 Smith C, Thompson E. North West Thames regional review of amily planning services: response to HSG(92)6. London: North West Thames Regional Health Authority, 1992.

35 Gill M. Purchasing for quality: still in the starting blocks ? Quality in Health Care 1993;2:179-82.

36 Newman K, Pyne T. Contracting for quality in the NHS: a study of purchaser practices. Fournal of the Association for Quality in Healthcare 1995;301:16-24.

37 Robinson R. The impact of the NHS reforms 1991-5. f Public Health Med 1996;18:337-42.

38 Webb E, Naish J, MacFarlane A. Planning and commissioning of health services for children and young people. $7 \mathrm{Pub}$ lic Health Med 1996;18:217-20.

39 Muir Gray JA. Evidence based healthcare: how to make health policy and management decisions. London: Churchill Livingstone, 1997. 